\title{
Systematization, description and territory of the caudal cerebral artery of the brain in broad-snouted Caiman (Caiman latirostris) ${ }^{1}$
}

\author{
Lygia Almeida $^{2 *}$ and Rui Campos ${ }^{2,3}$
}

\begin{abstract}
Almeida L. \& Campos R. 2011. Systematization, description and territory of the caudal cerebral artery of the brain in broad-snouted Caiman (Caiman latirostris). Pesquisa Veterinária Brasileira 31(9):817-822. Setor de Anatomia Animal, Departamento de Ciências Morfológicas, Faculdade de Veterinária, Universidade Federal do Rio Grande do Sul, Av. Bento Gonçalves 9090, Porto Alegre, RS 90540-000, Brazil. E-mail: lalmeida@terra.com.br

Thirty heads with the neck segment of Caiman latirostris were used. The animals were provided from a creation center called Mister Caiman, under the authorization of the Brazilian Institute of Environment and Renewable Natural Resources (Ibama). Animals were sacrificed according to the slaughtering routine of the abattoir, and the heads were sectioned at the level of the third cervical vertebra. The arterial system was washed with cold saline solution, with drainage through jugular veins. Subsequently, the system was filled with red colored latex injection. Pieces were than fixed in $20 \%$ formaldehyde, for seven days. The brains were removed, with a spinal cord segment, the duramater removed and the arteries dissected. At the level of the hypophysis, the internal carotid artery gave off a rostral branch, and a short caudal branch, continuing, naturally, as the caudal cerebral artery. This artery projected laterodorsalwards and, as it overpassed the optic tract, gave off its I (the first) central branch. Penetrated in the cerebral transverse fissure, emitting the diencephalic artery and next its II (second) central branch. Still inside the fissure, originated occipital hemispheric branches and a pineal branch. Emerged from the cerebral transverse fissure, over the occipital pole of the cerebral hemisphere. Projected rostralwards, sagital to the cerebral longitudinal fissure, as interhemispheric artery. This artery gave off medial and convex hemispheric branches to the respective surfaces of the cerebral hemispheres, anastomosed with its contralateral homologous, forming the common ethmoidal artery. This artery entered the fissure between the olfactory peduncles, emerging ventrally and dividing into ethmoidal arteries, right and left, which progressed towards the nasal cavities, vascularizing them. The territory of the caudal cerebral artery included the most caudal area of the base of the cerebral hemisphere, its convex surface, the olfactory peduncles and bulbs, the choroid plexuses and the diencephalus with its parietal organs.
\end{abstract}

INDEX TERMS: Alligator, cerebral arteries, brain vascularization, reptiles

RESUMO.- [Sistematização, descrição e território da artéria cerebral caudal no cérebro do jacaré do papo-amarelo (Caiman latirostris).] Foram utilizadas trinta cabeças com o segmento de pescoço de Caiman latirostris. Os animais eram provenientes do Criatório Mister Caiman sob a autorização do Instituto Brasileiro de Meio Ambiente e dos Recursos Naturais

\footnotetext{
${ }^{1}$ Received on November 3, 2010.

Accepted for publication on April 13, 2011.

${ }^{2}$ Programa de Pós-Graduação em Medicina Veterinária, Faculdade de Veterinária, Universidade Federal do Rio Grande do Sul (UFRGS), Av. Bento Gonçalves 9090, Porto Alegre, RS, 91540-000, Brazil. *Corresponding author: lalmeida@terra.com.br

${ }^{3}$ Departamento de Ciências Morfológicas, Centro de Ciências Básicas, UFRGS, Av. Bento Gonçalves 9090, Porto Alegre, RS 91540-000. E-mail: rcampos@ufrgs.br
}

Renováveis (Ibama). Os animais foram sacrificados de acordo com as normas de rotina de abate do frigorífico e as cabeças foram seccionadas na altura da terceira vértebra cervical. 0 sistema arterial foi lavado com solução salina $0.9 \%$ resfriada, com drenagem pelas veias jugulares. Em seguida, o sistema foi preenchido com injeção de látex, corado em vermelho As peças foram então fixadas em formaldeído a $20.0 \%$ por sete dias. 0 cérebro foi removido, com um segmento de medula espinhal, a dura-máter retirada e as artérias dissecadas. Na altura da hipófise, a artéria carótida interna emitiu um ramo rostral e, um curto ramo caudal, continuando-se naturalmente, como artéria cerebral caudal. Esta se projetou látero-dorsalmente e ao sobrepassar o trato óptico, emitiu seu I (primeiro) ramo central. Penetrou na fissura transversa do cérebro, lançando a artéria diencefálica e a seguir seu II (segundo) ramo central. 
Ainda dentro da fissura originou ramos hemisféricos occipitais, e um ramo pineal. Emergiu da fissura transversa do cérebro, no pólo occipital do hemisfério cerebral. Projetou-se rostralmente, sagital a fissura longitudinal do cérebro, como artéria interhemisférica. Esta artéria lançou ramos hemisféricos convexos e mediais para as respectivas faces dos hemisférios cerebrais, anastomosou-se com sua homóloga contralateral, formando uma artéria etmoidal comum. Esta mergulhou na fissura entre os pedúnculos olfatórios emergindo ventralmente e, dividindo-se em artérias etmoidais, direita e esquerda, as quais progrediram para as cavidades nasais, vascularizando-as. 0 território da artéria cerebral caudal compreendeu a área mais caudal da base do hemisfério cerebral, sua face convexa, os pendúculos e bulbos olfatórios, plexo corióides e o diencéfalo com seus órgãos parietais.

TERMOS DE INDEXAÇÃO: Artérias cerebrais, vascularização cerebral, répteis, jacaré.

\section{INTRODUCTION}

The farming production of the broad-snouted Caiman, a Brazilian fauna species, and the authorization for the commercialization of their high quality skin and meat by the Brazilian Institute of Environment and Renewable Natural Resources (Ibama), increased the interest in its production by the national and international markets.

The distribution of the cerebral blood supply, as in any other anatomical structure, is closely associated to the development stage and the consequent morphology presented by the central nervous system of each species. The classical textbook little or no concern in relation to irrigation brain on this animal, although in the specialized literature, Burda (1969) studied the development of the intracranial arterial pattern in alligator embryos and the cerebrovascular changes that occur after birth. De Vriese (1905) provided important contributions to the phylogeny and ontogeny of the cerebral arteries, classifying several animal groups, according to the cerebral arterial circle formation into three distinct types. Kappers (1933), Schepers (1939) and Burda (1965) reported the arterial supply to the brain in turtles. Frizzo et al. (1994) investigated the vascularization of the subfornical organ of turtles. Gillilan (1967) affirmed that the cerebral arterial patterns of reptiles are similar and represent a stage of transition between primitive and superior vertebrates. Dendy (1909) and Burda (1966) studied the intracranial arterial system of Sphenodon punctatus (iguana) and Crotaphytus collaris (lizard), respectively. In addition, there were some descriptions about the cerebral vascularization in Caiman latirostris (Almeida \& Campos 2010, Almeida \& Campos 2011).

This study aims to describe and systematize the caudal cerebral artery of the broad-snouted Caiman, determining a standard model and territorial area of irrigation, and the main variations, in this species. These informations contribute for the studies in this area of the comparative anatomy about the phylogenetic development of the blood supply to the central nervous system.

\section{MATERIALS AND METHODS}

Thirty heads with the neck segment of Caiman latirostris were used. The animals were around three years old, weighting 8-10 kg, ma- les, provided from a creation center called Mister Caiman, under the authorization of the Brazilian Institute of Environment and Renewable Natural Resources (Ibama). Animals were sacrificed according to the slaughtering routine of the abattoir, and the thirty heads were sectioned at the level of the third cervical vertebra. The azygous carotid artery was cannulated just before its division into internal carotid arteries, and the arterial system was washed with cold saline solution, containing 2500 IU heparin (Heparin; Cristalia Produtos Quimicos Farmaceuticos Ltda, Itapira, SP, Brazil) per animal, with drainage through jugular veins. Subsequently, the system was filled with latex injection (Cola 603, Bertoncini Ltda, São Paulo, SP, Brazil) colored with red pigment (Suvinil Corante BASF S.A., São Bernardo do Campo, SP, Brazil). Pieces remained for at least one hour in running water for latex polymerization. Next, a bone window was opened in the skullcap. Pieces were than fixed in $20 \%$ formaldehyde, for seven days. The brains were removed, with a spinal cord segment, the duramater removed and the arteries dissected. Schematic drawings of the ventral and dorsal views of the brain arteries and of the interior of the cerebral fissure of all specimens were prepared with the aid of a magnifying glass (LTS, $5 x$ increase and Stemi SV8 Zeiss; Goettingen, Germany). Since it is a reptile which the morphological aspects became closer to birds than mammals, the vessels were named according to the Nomina Anatomica Avium (1993) and Nomina Anatomica Veterinaria (2005), with some designations based on the author's interpretation of previous reports. Some specimens were photographed to illustrate the vessel arrangements. The occurrence and distribution of the vessels was expressed as a percentage of the thirty specimens examined.

\section{RESULTS}

As it became close to the nape of neck, the azygous carotid artery divided into two internal carotid arteries, in an approximate divergent angle of $70^{\circ}$, which penetrated in the carotid foramina, laterally to the single occipital condylus and the foramen magnun. The internal carotid artery ran along the carotid canal until it reached the sella turcica, where it emerged caudolateralwards the hypophysis. It curved dorsally, juxtaposed to the tuber cinerium, and on its base, emitted a rostral branch, of medium caliber, continuing as caudal branch, of thick caliber (Fig.1).

The caudal cerebral artery, in Caiman, was a natural continuation, of the thick caliber portion of the caudal branch of the internal carotid artery. In all samples, it was present and constant as a single vessel of thick caliber. The thick caliber of the caudal cerebral artery was due to the blood supply to the nasal cavity by the ethmoidal artery, its terminal branch (Fig. 2 and 3A). The caudal cerebral artery projected laterodorsalwards and as it passed over the optic tract, emitted its I (the first) central branch, which ran rostralwards, medial to the piriform lobe. The I (the first) central branch anastomosed with the first branches of the middle cerebral artery network, and its caudal ramifications reached the most rostral part of the piriform lobe, reaching the lateral part of the base of the brain. The I (the first) central branch of the right caudal cerebral artery was a single vessel in $73.3 \%$ of the cases, double in $16.7 \%$ and absent in $10 \%$. To the left, the I (the first) central branch of the caudal cerebral artery was single in $66.7 \%$, absent in $26.7 \%$ and double in $10 \%$ of the samples. When it was absent, its vascular territory was supplied by the presence of the rostral branch 


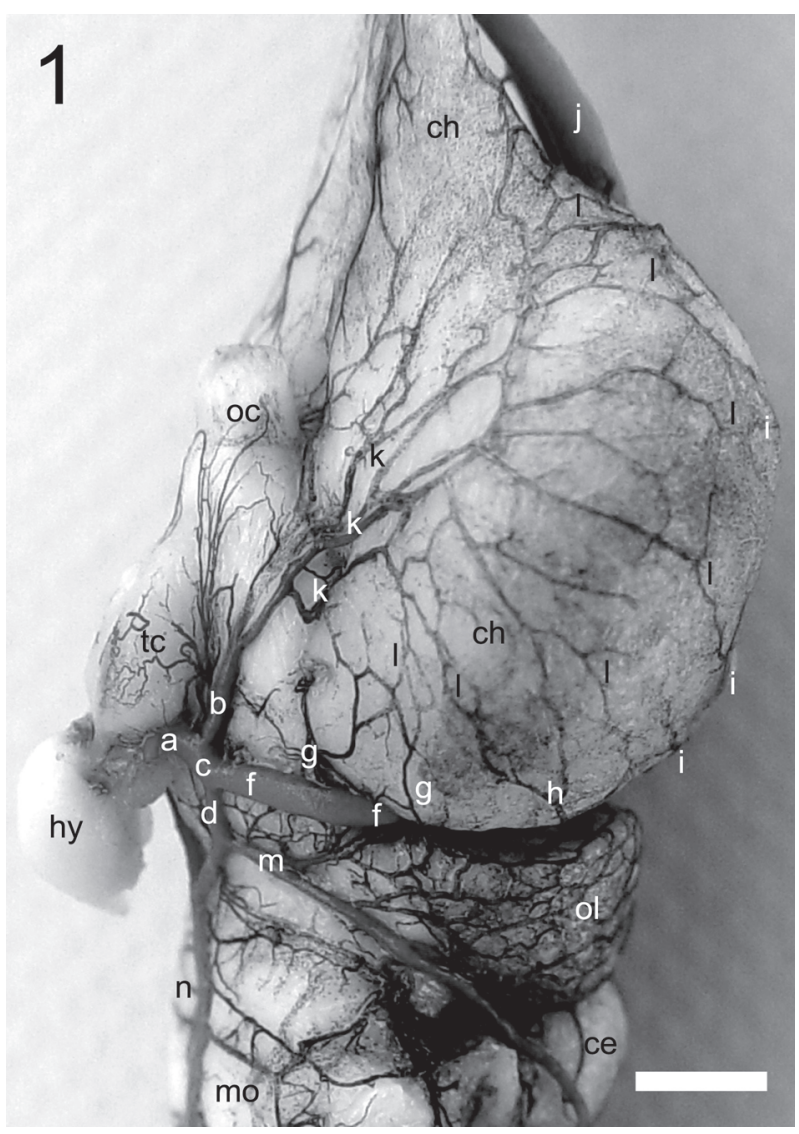

Fig.1. Detail of the lateral view of the Caiman brain showing the origin of the caudal cerebral artery. (a) Internal carotid artery; (b) rostral branch of a; (c) caudal branch (thick caliber portion) of the a; (d) caudal branch (medium caliber portion) of the a; (f) caudal cerebral artery; (g) II central branch of the f; (h) occipital hemispheric branch of the f; (i) convex hemispheric branch of the interhemispheric artery; (j) interhemispheric artery; (k) middle cerebral artery network; (l) terminal branches of the k; (m) mesencephalic artery; (n) basilar artery; oc, optic chiasm; (tc) tuber cinereum; (ch) cerebral hemisphere; (hy) hypophysis; (mo) medulla oblongata; (ce) cerebellum; (ol) optic lobe. Bar: $3.2 \mathrm{~mm}$

of the internal carotid artery, double, or by the ramification of the middle cerebral artery network, which progressed caudalwards (Fig.1).

After penetrated in the cerebral transverse fissure, the caudal cerebral artery gave off the diencephalic artery (Fig.3B), which projected caudomedialwards reaching the median line, vascularizing the habenula, choroid plexus of the third and lateral ventricles and the parietal organs. The right diencephalic artery was single in $53 \%$ of the pieces and double in $46.7 \%$. To the left it was single in $66.7 \%$ of the specimens and double in $33.3 \%$.

After gave off the diencephalic artery, the caudal cerebral artery originated a small II (second) central branch, which was projected to the base of the cerebral hemisphere, vascularizing the most caudal part of the piriform lobe (Fig.1). To the right, in $56.7 \%$ of the samples, it was a single vessel, in $20 \%$ it was absent, in $16.7 \%$ was double and in $6.7 \%$ triple. To the left, in $56.7 \%$ was single, in $20 \%$ was double, in $20 \%$ was absent and in $3.3 \%$ was a triple vessel. When it was absent, its vascular territory was supplied by the

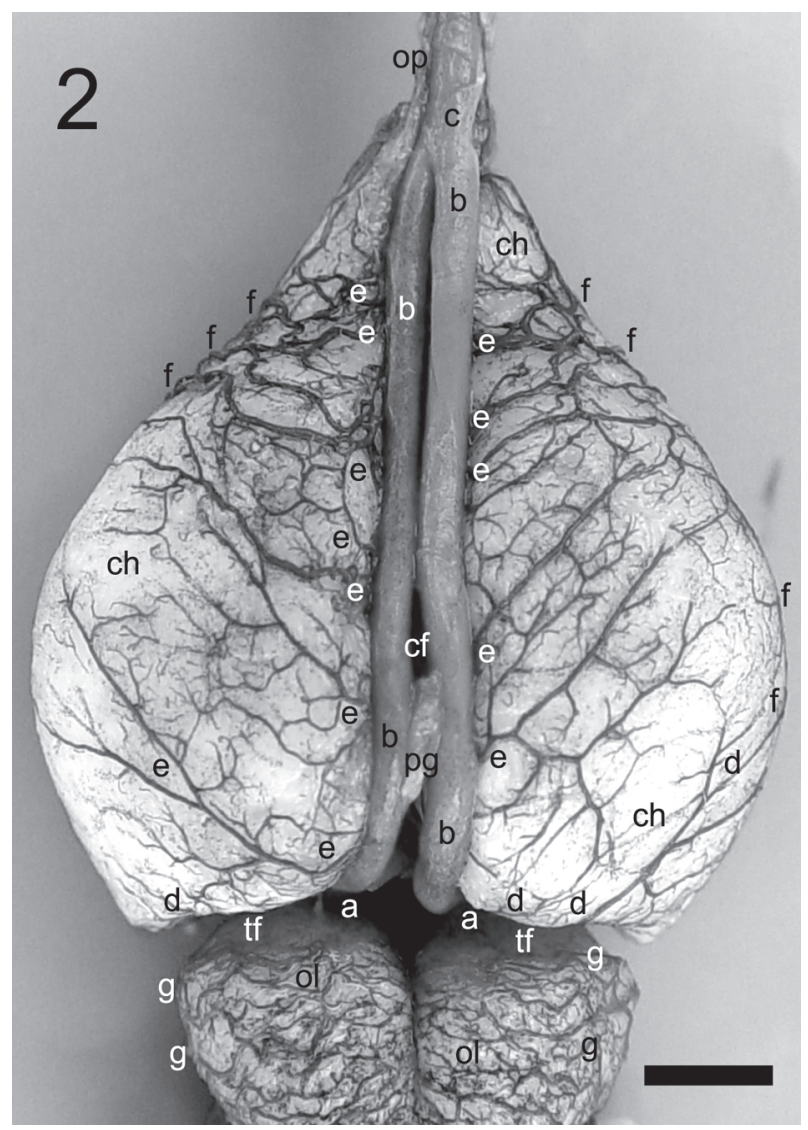

Fig.2. Dorsal view of the Caiman cerebral hemisphere showing pattern distribution of the caudal cerebral artery. (a) Caudal cerebral artery; (b) interhemispheric artery; (c) common ethmoidal artery; (d) occipital hemispheric branch of the a; (e) convex hemispheric branch of the b; (f) terminal branch of the middle cerebral artery network; (g) tectal branch of the mesencephalic artery ; (op) olfactory peduncle; (ch) cerebral hemisphere; (pg) pineal gland; (cf) cerebral longitudinal fissure; (tf) cerebral transverse fissure; (ol) optic lobe. Bar: $3.5 \mathrm{~mm}$.

ramifications of the diencephalic artery, or by the occipital hemispheric branches from the caudal cerebral artery of the same antimere.

After gave off the II (second) central branch, the caudal cerebral artery gave off, inside the cerebral transverse fissure, a sequence of occipital hemispheric branches (Fig.3B). These branches projected dorsalwards, reaching the caudal pole of the cerebral hemisphere, ramifying rostrolateralwards on its convex surface. Its terminal ramifications reached the lateral border of the caudal part of the cerebral hemisphere, anastomosing with the ramifications of the network of the middle cerebral artery (Fig.2 and 3A). On the right antimere, the occipital hemispheric branches were double in $50 \%$ of the cases, triple in $36.7 \%$ and single in $13.3 \%$, while to the left, it was triple in $56.7 \%$ of the pieces, double in $40 \%$ and single in $3.3 \%$.

The pineal artery was projected from the caudal cerebral artery after the emission of the last occipital hemispheric branch, inside the cerebral transverse fissure. Reached the base of the pineal gland, ascended by its peduncle until it reached its exposed apex, at the beginning of the cerebral longitudinal fissure (Fig.3B). It was a single vessel in all samples in the right 

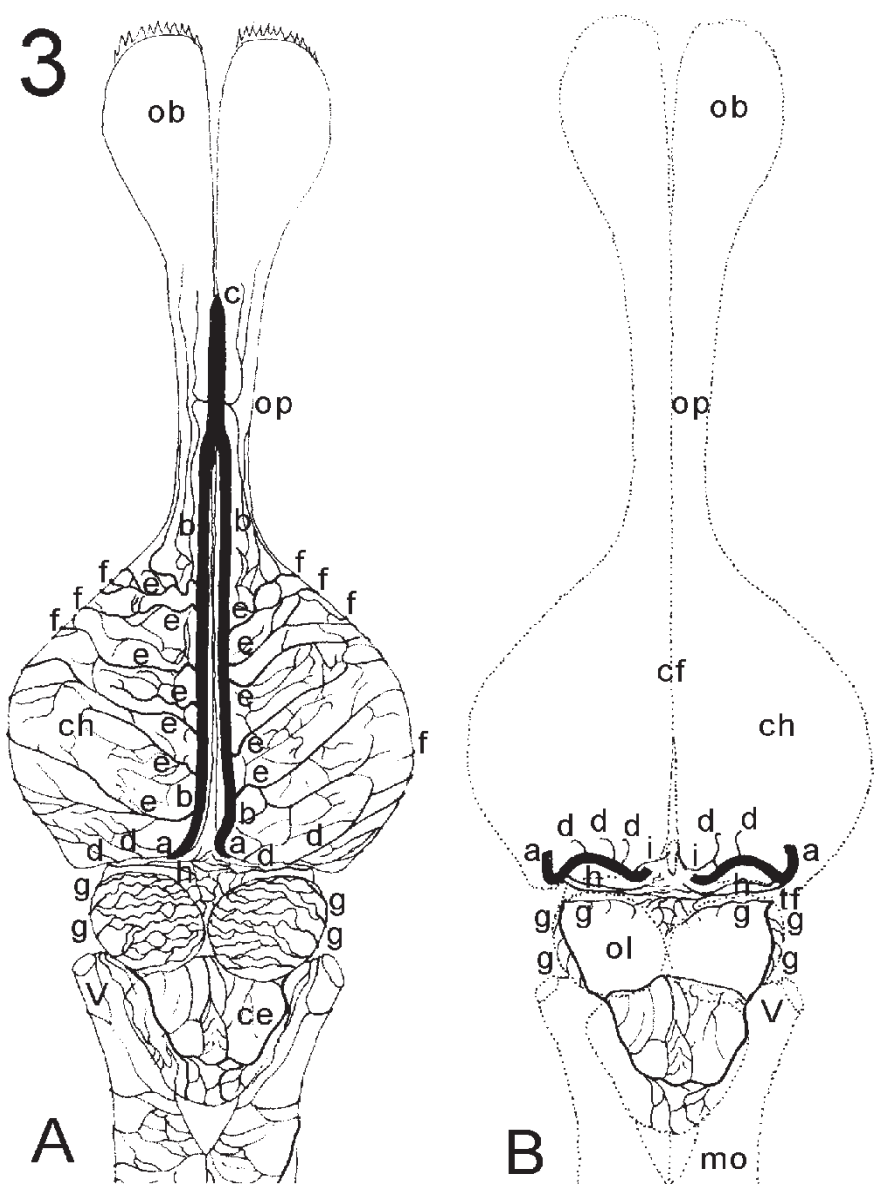

Fig.3. Schematic drawing in a dorsal view (A) of the arteries inside the cerebral transverse fissure (B) in Caiman brain. (a) caudal cerebral artery; (b) interhemispheric artery; (c) common ethmoidal artery; (d) occipital hemispheric branch of the a; (e) convex hemispheric branch of the b; (f) terminal branch of the middle cerebral artery network; ( $g$ ) tectal branch of the mesencephalic artery; (h) diencephalic artery; (i, Pineal artery; (ob) olfactory bulb; (op) olfactory peduncle; (ch) cerebral hemisphere; (cf) cerebral longitudinal fissure; (tf) cerebral transverse fissure; (mo) medulla oblongata; (ce) cerebellum; (ol) optic lobe; (V) trigeminal nerv.

antimere, while in the left it was single in $93.3 \%$ of the samples and double in $6.7 \%$. After the pineal artery origin, the caudal cerebral artery curved caudodorsalwards, following the peduncle of the pineal gland, emerging at the occipital pole of the cerebral hemisphere. It was projected rostralwards, sagital

Table 1. Convex hemispheric branches of the interhemispheric artery

\begin{tabular}{ccc}
\hline $\begin{array}{c}\text { Number } \\
\text { of branches }\end{array}$ & $\begin{array}{c}\text { RIA (\%) } \\
\text { Average range } \\
(\overline{\mathbf{X}} \pm \mathrm{s})\end{array}$ & $\begin{array}{c}\text { LiA }(\%) \\
(\overline{\mathbf{X}} \pm \mathrm{s})\end{array}$ \\
\hline 2 & $3.3 \pm 3.3$ & - \\
3 & $6.7 \pm 4.5$ & $3.3 \pm 3.3$ \\
4 & $23.3 \pm 7.7$ & $23.3 \pm 7.7$ \\
5 & $43.4 \pm 9.0$ & $26.7 \pm 8.1$ \\
6 & $13.3 \pm 6.2$ & $26.7 \pm 8.1$ \\
7 & $10.0 \pm 5.5$ & $20.0 \pm 7.3$ \\
\hline
\end{tabular}

RIA = right interhemispheric artery; LIA = left interhemispheric artery. to the cerebral longitudinal fissure, as interhemispheric artery, a single vessel, on both antimeres (Fig.2 and $3 \mathrm{~A}$ ).

The interhemispheric artery along its longitudinal course, emitted convex hemispheric branches (Table 1) to the convex surface of the cerebral hemisphere and medial hemispheric branches (Table 2) to the medial surface of the same. The calibers of the convex and medial hemispheric arteries presented an uncommon disproportion regarding the origin vessel, the interhemispheric artery. The convex hemispheric branches projected laterorostralwards, until it reached the lateral border of the cerebral hemisphere, where its ramifications anastomosed "in osculum" with the terminal branches of the middle cerebral artery network. The most rostral branches anastomosed with the most rostral ramifications of the middle cerebral artery network on the convex surface of the cerebral hemisphere (Fig.2 and 3A). Their anastomosis had considerable caliber made by main arterial axes. In some cases, com-

Table 2. Medial hemispheric branches of the interhemispheric artery

\begin{tabular}{ccc}
\hline \multirow{2}{*}{$\begin{array}{c}\text { Number } \\
\text { of branches }\end{array}$} & $\begin{array}{c}\text { RIA (\%) } \\
\text { Average range } \\
(\overline{\mathbf{X}} \pm \mathrm{s})\end{array}$ & $\begin{array}{c}\text { Average range } \\
(\overline{\mathbf{X}} \pm \mathrm{s})\end{array}$ \\
\hline 0 & $10.0 \pm 5.5$ & $6.7 \pm 4.5$ \\
1 & $46.7 \pm 9.1$ & $43.3 \pm 9.0$ \\
2 & $33.3 \pm 8.6$ & $30.0 \pm 8.4$ \\
3 & $6.7 \pm 4.5$ & $13.3 \pm 6.2$ \\
4 & $3.3 \pm 3.3$ & $6.7 \pm 4.5$
\end{tabular}

RIA = right interhemispheric artery; LIA = left interhemispheric artery.

plementary medial hemispheric branches were also emitted from the convex hemispheric branches. On the caudal third of the olfactory peduncle, the interhemispheric artery anastomosed with its contralateral homologous, forming an single artery, the common ethmoidal artery.

The common ethmoidal artery, a thick caliber vessel, was present in $100 \%$ of the samples, and emitted thin branches which vascularized the olfactory peduncles. On the middle third of the olfactory peduncles, it penetrated in the cerebral longitudinal fissure, emerging ventrorostralwards, dividing in ethmoidal arteries, right and left. They recieved an anastomosis, of thick caliber, from the orbitary artery, progressed to the nasal cavities, vascularizing them. The left ethmoidal artery, in $73.3 \%$ of the cases originated the medial artery of the olfactory bulb, but in $26.7 \%$ the medial olfactory bulb artery was originated from the right ethmoidal artery. The medial olfactory bulb artery, an single vessel, vascularized the two olfactory bulbs.

The territory of the caudal cerebral artery, in Caiman, included the ventral surface of the caudal part of the cerebral hemisphere, which corresponds to the piriform lobe, the diencephalus structures and their parietal organs (habenula, pineal gland, dorsal sac and paraphysis) and the choroid plexuses of the III and the lateral ventricles. The convex surface of the cerebral hemisphere, except the its laterorostral part, the peduncles and olfactory bulbs. Vascularized the entire nasal cavity throught the ethmoidal artery, its terminal branch. 


\section{DISCUSSION}

Regarding the blood supply sources to the brain of Caiman, in all reviewed literature, there is no reference to the subject and the authors have only described a carotid artery at the base of the skull. In two Caiman specimens examined, a single source was found, provided by the left carotid arch, which followed the deep musculature of the neck, at the median line, until reached the caudal base of the skull and was denominated azygous carotid artery (Campos, personal communication). It divided into two internal carotid arteries, which vascularized the entire head, except the mandibula.

Regarding the blood vessels, in three adult alligators, Burda (1969) reported that the internal carotid artery travelled across the carotid canal on the basisphenoid bone floor, at the caudal limit of the pituitary fossa (sella turcica), curved dorsalwards and penetrated in the cranial cavity ( Dendy 1909, Burda 1965, Burda 1966, Gillilan 1967, Almeida \& Campos 2010, Almeida \& Campos 2011). These results coincide with the ones observed in broad-snouted Caiman (Caiman latirostris).

Burda (1965), studying the cerebral vessels in six turtles of the genus Pseudemys, affirmed that the internal carotid artery, after the orbital artery's origin, ran rostralwards as cerebral carotid artery, which divided in rostral encephalic (rostral branch) and caudal encephalic (caudal branch) arteries (Burda 1966, Burda 1969). Whereas Gillilan (1967), in the comparative study of the cerebral blood supply of the lizard, turtle and alligator, reported that the internal carotid artery divided in a rostral and a caudal branch (De Vriese 1905, Dendy 1909, Kappers 1933, Scheppers 1939, Almeida \& Campos 2010, Almeida \& Campos 2011), the same was observed, in the majority of the pieces, in Caiman latirostris. Frizzo et al. (1994), researching the irrigation of the subfornical organ in 32 turtles Chysemys dobigni, described that the internal carotid artery formed three divisions: terminal, rostral and caudal.

According to De Vriese (1905), in turtles, the rostral and the caudal branches of the internal carotid artery had equal calibers, whereas in saurians and crocodiles the rostral branch had bigger caliber than the caudal branch. For Gillilan (1967) in reptiles, the caudal branch of the internal carotid artery was slightly bigger than the rostral branch. In agreement with Gillilan (1967) the caudal branch was more developed than the rostral branch, in Caiman, and presented two portions, one thick and another of medium caliber (Almeida \& Campos 2010, Almeida \& Campos 2011).

According to Dendy (1909) in sphenodon (iguana), the rostral portion (rostral branch) of the internal carotid artery emitted the caudal, middle and rostral cerebral arteries (Kappers 1933, Schepers 1939, Burda 1966, Gillilan 1967). Whereas Gillilan (1967), the caudal tectal and cerebellar arteries were projected from the caudal branch of the internal carotid artery, and ran dorsalwards to the optic and cerebellar lobes, respectively.

Burda (1965) reported in turtles, that the caudal branch went caudalwards and emitted, as collateral branches, the diencephalic, mesencephalic and cerebellar arteries, while in Caiman, the diencephalic artery was a branch from the caudal cerebral artery (Almeida \& Campos 2011). For Schepers
(1939), in turtles, the caudal branch of the internal carotid artery gave off, besides these branches, the choroid plexus artery of the fourth ventricle. Still for Schepers (1939), the rostral branch of the internal carotid artery emitted, at the level of the optic tract, the caudal cerebral artery, which proceeded laterodorsally towards the caudal pole of the cerebral hemisphere (Dendy 1909, Kappers 1933, Burda 1966). According to Burda (1965), in turtles, the path was similar to what reported by Schepers (1939), however the caudal cerebral artery was originated from the caudal branch, as in Caiman. Burda (1969), studying several embryonic stages, in alligator, observed discrepancies in the origin of the caudal cerebral artery, difficult to explain. In the embryo, the caudal cerebral artery branched from the caudal branch of the cerebral carotid artery. But in adults, it was originated at the angle between the rostral and caudal branches, or was emitted from the rostral branch. Additionally reported, that the caudal cerebral artery was originated at the divergent angle between the rostral and caudal branches, proceeded dorsalwards, penetrating in the fissure between the cerebral hemispheres and the optic lobes (Almeida \& Campos 2011). The caudal cerebral artery emitted several branches to the caudolateral and caudomedial regions of the cerebral hemisphere and to the rostral surface of the optic lobe. Also emitted a choroid branch to the plexus of the third ventricle. Curved caudodorsalwards, emerging at the occipital pole of the cerebral hemisphere, projecting rostralwards along the dorsal surface of the cerebral hemisphere. The right and left caudal cerebral arteries, followed a parallel dorsal path. Next to the rostral limit of the hemispheres, these two vessels anastomosed, to form the common ethmoidal artery, which readed ventralwards through the cerebral longitudinal fissure, towards the rostral region of the cranial cavity (Gillilan 1967). This same artery gave off a medial olfactory artery between the olfactory bulbs and bifurcated in right and left ethmoidal arteries. In Caiman, the caudal cerebral artery presented the same behavior described by Burda (1969), except that was denominated interhemispheric artery, at the trajectory between the cerebral transverse fissure and its anastomosis, which originated the common ethmoidal artery (Almeida \& Campos 2010, Almeida \& Campos 2011).

Regarding the caudal cerebral artery, Dendy (1909) reported that the rostral branch originated a caudal cerebral artery, which ran dorsalwards between the optic lobe and the cerebral hemisphere. At the rostrodorsal border of the optic lobe divided into two vessels, the sacular artery, that supplies the choroid plexus of the dorsal sac and the dorsal cerebral artery to the choroid plexus of the third and lateral ventricles (Kappers 1933). Also to Burda (1966), in Crotaphytus collaris (lizard), the caudal cerebral artery was originated from the rostral branch, after the emission of the mesencephalic artery. At the level of the rostrolateral border of the optic lobe, the caudal cerebral artery turned abruptly dorsalwards, disappearing into the fissure between the optic lobe and cerebral hemisphere. Instead, in Caiman, the caudal cerebral and mesencephalic arteries were always a dependency of the caudal branch of the internal carotid artery. Still for Buda (1966), the caudal cerebral artery, ran dorsalwards, and into the cerebral transverse fissure emitted a series of small 
branches to the parietal organs, branches to the choroid plexus of the third and lateral ventricles. In Caiman, the caudal cerebral artery emitted, before entering the cerebral transverse fissure, a branch denominated I (the first) central branch and inside the fissure gave off the diencephalic artery, the II (second) central branch, the occipital hemispheric branches and the pineal artery (Almeida \& Campos 2011).

According to Schepers (1939), in turtles, the caudal cerebral artery originated from the rostral branch, projected laterodorsalwards over the optic tract and penetrated into the fissure between the optic lobe and the cerebral hemisphere. Whereas for Burda (1965) in turtles, the caudal branch of the cerebral carotid artery ran caudalwards, and gave off the caudal cerebral artery, which projected ventrally to the caudal pole of the cerebral hemisphere, continuing along its mediodorsal surface. Emitted numerous branches to this hemispheric region and gave off a branch to the pineal gland and a branch to the choroid plexus of the third ventricle. The caudal cerebral artery on both sides, ran rostralwards closely associated to each other, and, eventually, anastomosed forming a single median vessel. This vessel anastomosed with the caudal ramifications of the arch that surrounded the base of the olfactory bulb, formed by the rostral cerebral arteries and the middle cerebral artery. The turtle has a large sessile olfactory bulb, while Caiman has a large pedunculated olfactory bulb; this anatomical difference is responsible for the relevant cerebral vascular changes between these species. Another important aspect is that the caudal cerebral artery, in Caiman, originates all the arterial vascularization of the nasal cavity, while in turtles, it is restricted to the cerebral hemispheres.

Regarding the diencephalic artery, Schepers (1939) reported that it was originated from the caudal branch, proceeded laterodorsalwards, disappearing caudal to the caudal pole of the cerebral hemisphere. Divided at the lateral surface of the thalamus into a thalamic branch and a branch to the dorsal sac and choroid plexus of the third ventricle. In Caiman, the diencephalic artery was the second branch emitted from the caudal cerebral artery, inside the cerebral transverse fissure, and ran towards to the roof of the third ventricle and parietal organs.

According to Gillilan (1967) and Almeida \& Campos (2011), branches that supplied the diencephalus and pineal gland were emitted from the caudal cerebral artery, as in Caiman. But to Dendy (1909), were the saccular arteries, originated from the caudal cerebral artery, that gave off the rostral and caudal pineal vessels, which vascularized the homonymous gland.

The caudal cerebral artery, when abandoned the cerebral transverse fissure, was denominated interhemispheric artery, responsible for the irrigation of the convex surface of the cerebral hemispheres, with its convex hemispheric branches, which was not mentioned in the consulted references. When reaching the olfactory peduncle, the two interhemispheric arteries anastomosed to form a common ethmoidal artery (Burda 1969, Almeida \& Campos 2011). These authors also cited that, the common ethmoidal artery ran between the two olfactory tract, towards the rostral region of the cranial cavity. Originated a small medial olfactory artery between the olfactory bulbs and bifurcated in right and left ethmoidal arteries. In Caiman, the common ethmoidal artery was originated from the anastomosis of the interhemispheric arteries, however only the ethmoidal artery, from one antimere, gave off the medial artery of the olfactory bulb, which vascularized the two olfactory bulbs. According to Dendy (1909), in sphenodon, the olfactory artery was the terminal branch of the middle cerebral artery and ran rostrodorsally towards the olfactory tract (Burda 1966). But for Schepers (1939), in turtles, was the rostral cerebral artery that gave off the terminal branches, lateral and medial, which supplied the peduncles and the olfactory bulbs (Gillilan 1967). According to Burda (1965), the rostral communicating artery originated the ethmoidal arteries, right and left. Each one of them immediately gave off, rostrally, a medial olfactory branch, which proceeded rostralwards along the ventromedial surface of the olfactory lobe and nerve.

The caudal cerebral artery of Caiman is the most developed and largest vessel of the brain of this animal, being also responsible for the blood supply of the nasal cavities, a fact that so far, was not mentioned in the consulted references in any other reptiles.

Acknowledgments.- To the Programa Institucional de Capacitação de Docentes e Técnicos (PICDT), Universidade Federal do Paraná, and Coordenação de Aperfeiçoamento de Pessoal de Ensino Superior (CAPES), for the financial support.

\section{REFERENCES}

Almeida L. \& Campos R. 2010. Systematization, description and territory of the middle and rostral cerebral arteries in Broad-snouted Caimans (Caiman latirostris). Acta Sci. Vet. 38 (3):262-268.

Almeida L. \& Campos R. 2011. A Systematic study of the brain base arteries in Broad-snouted Caiman (Caiman latirostris). J. Morphol. Sci. 28 (1): 6268.

Baumel J.J. 1993. Handbook of Avian Anatomy: Nomina Anatomica Avium. $2^{\text {nd }}$ ed. Nuttal Ornithological Club, Cambridge. 779p.

Burda D. 1965. Development of intracranial arterial patterns in turtles. J. Morphol. 116:171-188.

Burda D. 1966. Embryonic modifications of lacertilian intracranial arteries. Am. J. Anat. 118:743-754.

Burda D. 1969. Developmental aspect of intracranial arterial supply in the alligator brain. J. Comp. Neurol. 135:369-380.

Campos R. 2009. Comunicação pessoal (Universidade Federal do Rio Grande do Sul, Porto Alegre, RS).

Dendy A. 1909. The intracranial vascular system of Sphenodon. Phil. Trans. R. Soc. Lond. B 200:403-426.

De Vriese B. 1905. Sur la signification morphologique des artères cérébrales. Archs Biol. 21:357-457.

Frizzo M.E.S., Campos R., Severino A.G. \& Achaval M.E. 1994. The vasculature of the subfornical organ of the turtle Chrysemys dorbigni. Ital. J. Anat. Embryol. 99:109-121.

Gillilan L.A. 1967. A comparative study of the extrinsic and intrinsic arterial blood supply to brains of the submammalian vertebrates. J. Comp. Neurol. 130:175-196.

Kappers C.U.A. 1933. The forebrain arteries of plagiostomes, reptiles, birds, and monotremes. Proc. Roy. Acad. 36:52-62.

Nomina Anatomica Veterinaria 2005. International Commitee on Veterinary Gross Anatomical Nomenclature (ICVGAN). $5^{\text {th }}$ ed. Available at http:/ /www.wavvaamav.org/Downloads/nav_2005.pdf (13 Oct. 2009).

Schepers G.W.H. 1939. The blood vascular system of the brain of Testudo geometrica. J. Anat. 73:451-495. 